\title{
La Libertad en el Mundo Moderno.
}

Si fuera permitido interpretar "libertad" como la exención de las cadenas distintas de las que impone el hombre mismo, ¿ no consideraríamos entonces el hecho de que el hom. bre de nuestros días se ha librado del poder de las enfermedacles contagiosas como una notable ampliación de la libertad? ¿Qué deciv del poder que henos conseguido en el último tercio de siglog que nos permitevecomrer las carreteras con tuna velocidad que pasa ocho veces la del caballo? ¿O cruzar el aire al doble de aquella velocidad? Sin embargo, tenemos que tomar más estrechamente el sentido de la palabra "libertad", puesto que las fuerzas que eliminaron las restricciones del hombre se distinguen mucho de aquellas que reducen las limitaciones que son inherentes a la naturaleza c'el mundo del hombre.

¿Hay en la sociedad contemporánea una demanda vigorosa de libertad? Diría que no hubo nada tan fuerte desde el albor de la Edad de Hicrro. Fué sugerida a las masas por las escuelas públicas, la instrucción universal, la lec. tura general de los periódicos, la costumbre de viajar, la extensión del voto, las campañas políticas y la difusión de las organizaciones gremiales. El anuncio moderno provoca la 
ostentación, sugiriendo incesantemente, que uno gane en rango, autoridad y consideración social, cuando adquiera esto o aquello. Al rodearse con los artículos anunciados, Ud. se sentirá comme il faut. Por esto, para la antigua nobleza basada exclusivamente en el abolengo resulta muy difícil mantenerse en la silla.

¿Qué podemos decir respecto a la fuente de la libertad? Mira cómo se derrumban dogmas religiosos venerables que insisten en que los paganos, incrédulos, herejes, disidentes, quákeros, judíos, mujeres y negros no deban tener los mismos derechos que los demás y gozar de la misma protección que el resto de la sociedad. I.as distinciones que se establecían en la India y que afectaban los miembros de diferentes grupos profesionales obtenían la sanción religiosa, no pudienclo ser abolidas ni siquiera después que la ocupación halbía dejado de manchirlos. Y de modo que en nuestros días la autoridad de la religión se disminuye, las restricciones humillantes impuestas sobre los intocables o las castas inferiores ya no pueden mantenerse estrictamente por más tiempo.

En los últimos ciento cincuenta años, el gobierno, en casi todo el mundo, tenía que corresponder en cierto grado a la voluntad del pueblo formalmente expresada. Naturalmente un gobierno limitado de este modo no pasará por alto las libertades acostumbradas tan fácilmente como solían hacerlo los gobiernos absolutos.

Con la difusión de la instrucción y la multiplicación de instituciones destinadas a la formación del intelecto público, la opinión pública viene a pesar más, y, después de andar primero a tientas, eventualmente se hace el enemigo incansable de las cadenas que el fuerte impone al débil para sus fines egoistas. No son, en primer término, los eclesiásticos y estadistas, sino la opinión pública la que encuentra los medios de poner fin a la esclavitud, la servidumbre, la venter de mujeres, el despedir la esposa contra su voluntad, el tu- 


\section{$-382-$}

telaje de los padres sobre los hijos adultos, el casamiento de los hijos por indicación de los padres, la explotación del trabajo de los niños en lugar de mandarlos al colegio, las restricciones impuestas al sexo femenino, la persecución de aquellos que no se someten voluntariamente a la autoridad eclesiástica, la expulsión de minorías disidentes por mayorías religiosas y el negar a ciertos elementos linguíísticos y étnicos dentro del pueblo los derechos y goces de que disfruta el resto.

Y no veo ninguna razón para afirmar que esta actitud del observador o testigo desinteresados desempeñará un papel menos importante en el futuro que está jugando en nuestros dias.

Desde luego, se impondrán nuevas restricciones, mas todas ellas reposan sobre una base funcional. Fíjese en la multitud de necesidades que, a demanda de las autoridades médicas, se impusieron últimamente con respecto a la conducta, al cuidado y a la custodia de los que sufren enfermedades contagiosas. Los expertos creen que de éstas se obtenCrá un marcado mejoranniento deela salud pública. De otro lado, los nuevos conocimientos de la herencia justifican la prohibición de matrimonios entre las personas taradas, D hasta la esterilización obligatoria.

Con nuestra creciente dependencia del "comercio intermediario" deben tomarse nuevas medidas para refrenar el cngaño de los últimos consumidores. Hace tiempo que el circulante, por demanda de los círculos comerciales, fué regulado y estandardizado, de manera que ahora cada pieza de moneda es exactamente lo que representa. No hay razón de que no se deba exigir de manera igual, que las mercaderías que llegan al consumiclor como equivalente de su moneda necesariamente cabal sea justamente lo que pretende ser. Sin embargo, en el tiempo actual, es completamente utópico inclusive soñar en tal cosa. Una regulación en este sentido encontrará la más decidida hostilidad y resistencia de 
parte de los productores y traficantes, enfurecidos por la perspectiva de ver mermados sus provechos. Como estos elementos son poderosísimos en la sociedad contemporánea, porque disponen de la colocación de la mayor parte de los anuncios, los que a su vez proporcionan el 75 u $80 \%$ de los ingresos de nuestros periódicos y revistas, resulta inútil esperar que sea combatido seriamente el engaño del consumidor. La protección del público consumidor queda leguas detrás de lo que debería ser, progresa lentamente y tiene la probabilidad de quedar sin efecto alguno, siempre que los explotadores tengan el predominio político.

El grito común contra lo que es estigmatizado como "legislación contra el lujo" es en todo sentido deshonesto. Resulta un engaño monstruoso pretender sostener que los esfuerzos de refrenar por leyes el tráfico de licores tengan algo de común con el afán de la nobleza del siglo XVII de dictar regulaciones para los gastos de las capas sociales inferiores. Detrás del movimiento antialcohólico no hay celos de clase sino el convencimiento de que el uso habitual de las bebidas tóxicas perjudica la vida superior de los hombres. El fracaso de la "enmienda décimo octavas,en los Estados Unidos, fué el triunfo de los consumidores "moderados", más los intereses organizados del licor, sobre la idea social.

Las leyes antinarcóticas se imponen solamente, porque el vicio del opio y de sus derivados no ha podido arraigarse en este país. El gobierno chino no podía impedir el consumo de los narcóticos en su pueblo por la misma razón por la que el gobierno americano no había podido controlar el comercio del licor, o sea, los intereses comprometidos se habían hecho demasiado fuertes.

Admito que la intensificación del "nacionalismo" de nuestros tiempos es desfavorable a la libertad personal. El nacionalismo no solamente antepone la lealtad a la nación a la lealtad a la familia, el clán, la comunidad o unidad locales, sino, que por regla general, exalta el egoismo nacio- 


\section{$-3^{84}-$}

nal frente a los méritos y derechos de otros pueblos. Como esto crea la política agresiva y la actitud belicosa, las naciones se ven obligadas, una tras otra, a ponerse la armadura molestosa de la "preparación" militar, que en muchos aspectos resulta un estorbo tan grande. $\mathrm{Y}$ esto conduce naturalmente a la crucificación de la libertad personal. Fs obvio que el remedio debe buscarse en la dirección de un gobierno universal.

Donde quiera que el comunismo y el fascismo han ganado el predominio, se ha produciclo una enorme reducción de todos los derechos que favorecen la formación y expresión de opiniones dañinas al partido dominante. En tanto que estas dos teorías rivales del orden social estín en una lucha de vida y muerte, los esfuerzos de reglamentar el pensamiento continuarán. Pero podemos esperar que dentro de algunos decenios, esta lucha se decidirá en una u otra ma. nera, y las tendencias hacia el desplegamiento de la libertad humana, que siguen intactas en el fondo, volverán a hacerse manifiestas.

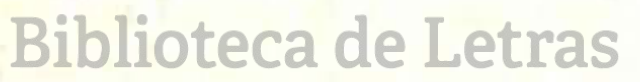

“Jorge PuccinelÉwarbrAisworti Ross.

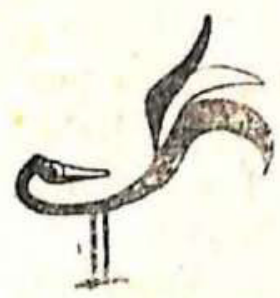

